\section{To avoid circumcision complications, avoid circumcision}

\author{
Robert Darby, PhD \\ Independent scholar and freelance, Canberra, Australia
}

Cite as: Can Urol Assoc J 2014;8(7-8):231.

http://dx.doi.org/10.5489/cuaj.1709

Published online August 11, 2014.

$\mathrm{T}$ he great value of the article by DeMaria and colleagues ${ }^{1}$ is their demonstration that even under the most favourable conditions - qualified medical personnel, modern hospitals, the latest equipment, an advanced Western society - circumcision of infants still cannot be performed without an unacceptable incidence of complications and adverse cosmetic outcomes. While it is a commendable achievement to indicate this problem, the paper is less satisfactory in other respects, as I shall briefly indicate.

First, although the authors refer to the recent policy statement on circumcision from the American Academy of Pediatrics, ${ }^{2}$ they do not acknowledge that it has been criticized by child health and human rights experts and cannot be taken as a consensus, much less as a definitive, position..$^{3,4}$ They appear to be unaware of MacDonald's argument that there is "no new evidence that infant circumcision provides any added benefit to the neonate, infant or young child with respect to HIV and HPV protection. The potential benefit from circumcision only begins to accrue when the male becomes sexually active." While there might be some sense in offering circumcision to young adolescent males (just before the onset of sexual activity), there is no medical justification for circumcision in infancy. ${ }^{5}$

Second, the authors refer to the 2004 circumcision policy of the Royal Australasian College of Physicians, but do not mention the policy issued in October 2010 that took a stronger line against routine infant circumcision, concluding that it is both medically unwarranted and ethically problematic. ${ }^{6}$ Furthermore, although infant circumcision remains common in Australia, the practice is in steady decline, with an incidence of less than $15 \%$ of boys by age 4 nationally, and far less in some states. ${ }^{7}$

Third, the authors suggest that the cause of surgical complications is lack of skill on the part of the operators, and thus that the problem can be fixed by training. No doubt lack of skill plays a part, but I suggest that the deeper problem lies in the anatomy of the penis. ${ }^{8}$ The survey confirms the conclusion of Hugh Young, in a study of circumcision techniques, that no fully satisfactory and entirely safe method has ever been devised and - given the complex and variable anatomy of the foreskin - none is ever likely to be. ${ }^{9}$ Unlike a finger, an arm, the gall bladder or the appendix, the foreskin is not a discrete or self-contained member or organ that can easily be detached from the rest of the body. Since it is an extension of the penile skin system, there is no agreed point at which the "foreskin" ends and the rest of the penis skin begins, and thus no clearly-defined point at which the operator should start (or stop) cutting. ${ }^{10}$ The structure of the foreskin does not lend it self to neat amputation, but is highly vulnerable to complications and messy cosmetic outcomes.

While I applaud the aim of DeMaria and colleagues in seeking to reduce the incidence of circumcision complications, and thus alleviate infant pain and suffering, I suggest that it would make more sense not to perform circumcision in the first place. A better option would be to direct their skills and resources towards instructing medical personnel and parents in the value of the normal genitalia, the simple rules for taking care of the foreskin, and generally driving home the message that routine circumcision of infants is likely to do more harm than good.

Competing interests: Dr. Darby is an independent scholar and author of numerous works on the history and ethics of male and female circumcision.

\section{References}

1. Demaria J, Abdulla A, Pemberton J, et al. Are physicians performing neonatal circumcisions well trained? Can Urol Assoc J 2013;7:260-4. http://dx.doi.org/10.5489/cuai.200

2. American Academy of Pediatrics Task Force on Circumcision. Circumcision policy statement. Pediatrics 2012;130:585-6. http://dx.doi.org/10.1542/peds.2012-1989

3. Frisch M, Aigrain Y, Barauskas V, et al. Cultural bias in the AAP's 2012 Technical Report and Policy Statement on male circumcision. Pediatrics 2013;131:796-800. http://dx.doi.org/10.1542/ peds.2012-2896

4. Svoboda JS, Van Howe RS. Out of step: Fatal flaws in the latest AAP policy report on neonatal circumcision. J Med Ethics 2013;39:434-41. http://dx.doi.org/10.1136/medethics-2013-101346

5. MacDonald N. Male circumcision: Get the timing right. CMAJ 2011;183:872. http://dx.doi.org/10.1503/cmaj.101425

6. Royal Australasian College of Physicians. Circumcision - RACP Position Statement. Sydney (Aust): RACP; 2010 September. www.racp.edu.au/page/paediatrics-and-child-health-division/ online-resources/paediatric-policy. Accessed 1 October 2013.

7. Incidence and prevalence of circumcision in Australia. http:// www.circinfo.org/statistics.html. Accessed 10 October 2013.

8. Cold CJ, Taylor JR. The prepuce. BJU Int 1999;83(Suppl1):34-44. http://dx.doi.org/10.1046/i.1464-410x.1999.0830s1034.x

9. Young H. Evolution of Circumcision Methods: Not "Just a Snip." In: Denniston GC. Milos MF, Hodges FM (eds), Genital Cutting: Protecting Children from Medical, Cultural, and Religious Infringements. Dordrecht: Springer; 2013

10. Darby R, Svoboda SJ. A rose by any other name: Symmetry and asymmetry in male and female genital cutting. In: Zabus C (ed.) Fearful Symmetries: Essays and Testimonies around Excision and Circumcision. Amsterdam and New York: Rodopi; 2009.

Correspondence: Dr. Robert Darby, robertdarby@homemail.com.au 